\title{
Spray Flow Structure from Twin-hole Diesel Injector Nozzles
}

\author{
D. Nguyen ${ }^{\mathrm{a},{ }^{*} \text {, D. Duke }}{ }^{\mathrm{b}}$, A. Kastengren ${ }^{\mathrm{c}}$, K. Matusik ${ }^{\mathrm{b}}$, A. Swantek ${ }^{\mathrm{b}}$, C.F. Powell ${ }^{\mathrm{b}}$, D. Honnery ${ }^{\mathrm{a}}$

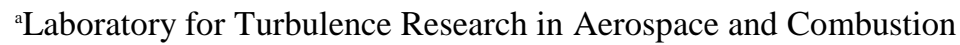 \\ Department of Mechanical and Aerospace Engineering \\ Monash University VIC 3800 Australia \\ ${ }^{\circ}$ Energy System Division, Argonne National Laboratory, Lemont IL 60439 USA \\ 'X-Ray Science Division, Argonne National Laboratory, Lemont IL 60439 USA
}

\begin{abstract}
Two techniques were used to study non-evaporating diesel sprays from common rail injectors which were equipped with twin-hole and single-hole nozzles for comparison. To characterise the sprays, high speed optical imaging and x-ray radiography were used. The former was performed at the Laboratory for Turbulence Research in Aerospace and Combustion (LTRAC) at Monash University, while the latter was performed at the 7-BM beamline of the Advanced Photon Source (APS) at Argonne National Laboratory. The optical imaging made use of high temporal, high spatial resolution spray recordings on a digital camera from which peripheral parameters in the initial injection phase were investigated based on edge detection. The x-ray radiography was used to explore quantitative mass distributions, which were measured on a point-wise basis at roughly similar sampling rate. Three twin-hole nozzles of different subtended angles and a single-hole nozzle were investigated at injection pressure of 1000 bar in environments of 20 bar back pressure. Evidence of strong cavitation was found for all nozzles examined with their $C_{D}$ ranging from 0.62 to 0.69 . Penetration of the twin-hole nozzles was found to lag the single-hole nozzle, before the sprays merged. Switching in hole dominance was observed from one twin-hole nozzle, and this was accompanied by greater instability in mass flow during the transient opening phase of the injectors.
\end{abstract}

Keywords: Twin-hole nozzle; diesel; spray; penetration; spray merge; $x$-ray radiography

\author{
*Corresponding Author \\ Dung Nguyen \\ Laboratory for Turbulence Research in Aerospace and Combustion, \\ Department of Mechanical and Aerospace Engineering, \\ Monash University, VIC 3800, \\ AUSTRALIA \\ Email: dungt.nguyen@monash.edu \\ Phone: +61-3-99051300
}

\section{Nomenclature}

$A_{l}, A_{n} \quad$ Liquid flow area at nozzle exit and nozzle exit area $\left(\mathrm{mm}^{2}\right)$

$C_{\rho}, C_{v} \quad$ Area and velocity coefficients

$C_{D} \quad$ Discharge coefficient

$d_{i}, d_{o} \quad$ Hole passage inlet and outlet diameters $(\mu \mathrm{m})$

$I, I_{O} \quad$ Transmitted and incident x-ray beam intensities

$k \quad$ Cavitation number

$K \quad K$-factor

$\dot{m} \quad$ Mass flow rate $(\mathrm{g} / \mathrm{s})$

$M \quad$ Projected mass $\left(\mu \mathrm{g} / \mathrm{mm}^{2}\right)$

$p_{i}, p_{c} \quad$ Injection and chamber pressures (bar) 


$\begin{array}{lll}54 & p_{v} & \text { Vapor pressure }(\mathrm{kPa}) \\ 55 & T I M & \text { Transverse integrated mass }(\mu \mathrm{g} / \mathrm{mm}) \\ 56 & U_{p}, \bar{U}_{n} & \text { Pressure driven and mean velocities of fuel at nozzle exit }(\mathrm{m} / \mathrm{s}) \\ 57 & \dot{V} & \text { Volume flow rate }(\mathrm{ml} / \mathrm{s}) \\ 58 & \alpha & \text { Void fraction } \\ 59 & \beta & \text { Twin-hole nozzle half angle }(\mathrm{deg}) \\ 60 & \theta & \text { Twin-hole nozzle hole angle }(\mathrm{deg}) \\ 61 & \rho_{l}, \rho_{v} & \text { Fuel liquid and vapor densities }\left(\mathrm{kg} / \mathrm{m}^{3}\right) \\ 62 & \bar{\rho}_{n} & \text { Mean density at the nozzle exit }(\mathrm{kg} / \mathrm{m} 3) \\ 63 & \mu & \text { Absorption coefficient }\end{array}$

\section{INTRODUCTION}

High pressure fuel injection has been a major area of research for some time, with many studies reporting on the effects of injector exit conditions on far-field macroscopic spray properties such as penetration, tip velocity and spread. Because of the experimental advantages to their use, particularly in optimizing the spatial resolution of the measurement domain, single-hole nozzles (SHNs) have been a significant focus of many of these past studies [1-7]. There is however a growing recognition of the need to study nozzles which are more representative of the multi-hole nozzles used in engines [e.g. 8-15] if advances are to be made in our understanding of spray structure and dynamics, and to improve engine performance.

Multi-hole nozzles are used in engines because they distribute the atomized fuel more evenly in the combustion chamber, facilitating better fuel-air mixing. Nozzle holes are generally uniformly spaced around the nozzle tip to ensure uniform mixing of the fuel and air. A group-hole nozzle (GHN) is a variation of this design, in which rather than being uniformly spaced, the nozzle holes are spaced closely together to form a group, with the groups, if more than one, being spaced around the tip. Because of their potential benefits to fuel consumption and emissions [16], GHNs, particularly in the form of a twin-hole nozzle (THN), have recently been a focus of interest [9,10,16-20]. An important feature of GHNs is they enhance spray to spray interaction whether through direct merging of closely spaced sprays [9], or indirectly through modification to air entrainment into individual but unmerged sprays as they compete for the surrounding air.

As well as having a more complex structure to the sprays produced, relative to a SHN, THNs are expected to have different internal fluid properties and more complex internal flow. For example, relative to a SHN with the same orifice diameter, the increased mass discharge which accompanies the increased number of holes in a GHN is likely to lead to reduced nozzle sac pressure [17]. Aside from altering nozzle exit velocities [13], this could also alter the nozzle needle lift profile particularly affecting the initial opening and closing transients [13,21]. Hole number and hole position have also been shown to strongly influence spray stability and near field spray breakup $[13,18,20,21]$. This influence is thought to arise from modification to the internal flow structure which accompanies change to these parameters. Vortical structures have been shown to be present in multi-hole nozzle internal flow [22], and the transport of these through the nozzle hole is thought to give rise to the vortex like morphology seen in the phase contrast images of sprays from multihole nozzle as they exit the nozzle [21]. For merged sprays in particular, an additional aspect is the possible dominance either in spread or penetration within the merged spray by an individual spray, leading to asymmetry in merged spray structure. Factors which could influence spray dominance are hole geometry [23,24], injector needle movement [25], needle eccentricity [26], and cavitation $[22,27]$. Cavitation either in the nozzle sac (string cavitation), or on entry to nozzle hole (geometric 
induced cavitation) could be expected to alter mass discharge and its distribution across the nozzle exit thus altering spray characteristics [22,24,28-32]. Knowledge of the vapour distribution across the nozzle exit could yield detail on the type of cavitation present. The propensity of a flow to cavitate, but not the form the cavitation takes, is generally assessed by its cavitation number, which can be determined directly from the vapour phase properties of the liquid and its operating pressure [28]. To obtain the phase state, distribution techniques such as phase contrast imaging and x-ray radiography can be used [7,33]. Phase contrast imaging provides internal and external visualization of vapour and liquid distributions, whereas x-ray radiography provides quantification of the mass distribution from which phase state can be determined, although this approach is limited to the nozzle's external flow.

With these observations in mind, the focus of this paper is to investigate the near field properties of non-evaporating diesel sprays issuing from THNs of varying geometry, defined here by different nozzle hole angle. We focus on the near field because this enables closer examination of the role of nozzle exit conditions on spray structure. Comparison data are presented for a SHN with the same nominal diameter so that the effects of differences between these two nozzle types can be explored in detail. Sprays are characterized by their penetration and merging properties during the opening transient, and mass distributions during both tran sient and steady state operations. Spray merging and penetration were measured using a high speed visible light technique. Spray mass distribution, and from this density, was measured using x-ray radiography, while nozzle geometry was determined by x-ray tomography. We find evidence of cavitation in all nozzles examined with vapour appearing to extend across the exit flow profile of the nozzles. Near field THN penetration was found to lag the SHN, even before the sprays merged for the THNs. Switching in hole dominance during the transient phase was observed for one THN, and this was accompanied by greater instability in nozzle exit mass flow.

\section{EXPERIMENTAL METHODOLOGY}

\subsection{Experimental Facilities}

The fuel spray experiments were done in two different facilities using two complementary techniques [15]. Input parameters were set to be the same, i.e. pressure and nozzles. The high speed optical imaging experiments were undertaken in the Laboratory for Turbulence Research in Aerospace and Combustion (LTRAC). A Bosch common rail injector was located at the top of a fully instrumented constant volume vessel measuring $150 \mathrm{~mm}$ in diameter and $132 \mathrm{~mm}$ in height; more detailed description can be found in $[1,34]$. The injector was equipped with three different twin-hole nozzles, which directed two sprays inclined by three different hole angles of $\theta=0^{\circ}, 5^{\circ}$ and $10^{\circ}$, Fig. 1. For comparison, a single-hole nozzle was used which has a similar hole diameter of $200 \mu \mathrm{m}$. High pressure diesel fuel was supplied to this injector through a common rail from a feedback controlled pump able to maintain the pressure to within \pm 5 bar of the set value. This pump received diesel from a boost pump connected to the diesel tank. Standard automotive diesel was circulated in the fuel system and its temperature was maintained between $30-32^{\circ} \mathrm{C}$ during experiments. The injection pressure used was 1000 bar and injection activation fixed at $0.3 \mathrm{~ms}$. The vessel was pressurised to 20 Bar using compressed air at $22^{\circ} \mathrm{C}$. 


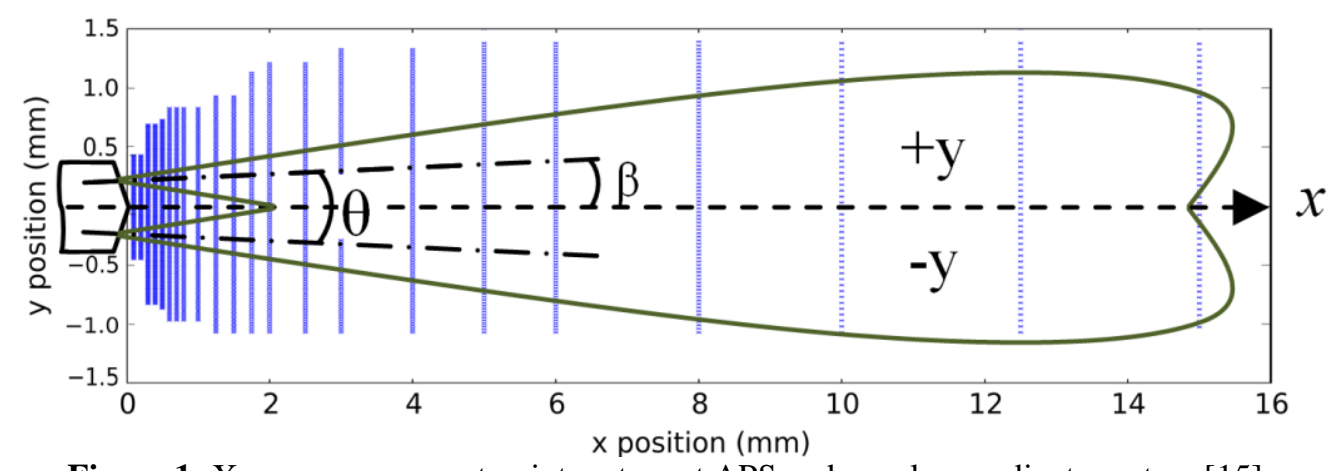

Figure 1: X-ray measurement points set up at APS and nozzle coordinate system [15].

Recording of the spray was done by use of a high speed HPV1 Shimadzu digital camera with a CCD array of $312 \times 260 \mathrm{px}^{2}$. A limitation with this camera is a maximum of 100 frames for each recording at any frame rate. Two high power TTL Met-Mecablitz flash units were used to provide spray volume illumination. The trigger signals for injector, flash units and the camera were produced and co-ordinated by use of a signal generator and a custom made control box. The start of recording could be tuned very close to the point of start of injection. For these measurements, the frame rate used was $500 \mathrm{kfps}$ resulting in $2 \mu \mathrm{s}$ time interval between frames ( $200 \mu \mathrm{s}$ total recording time). The integration time used was $1 / 8$ of this interval, i.e. $0.25 \mu \mathrm{s}$, to minimize blurring effects. Fitted to this camera was a micro Nikkon lens of $200 \mathrm{~mm}$ focal length with f-stop set at 5.6. The system was focused on a viewing area $\left(\mathrm{W}_{\mathrm{xH}}\right)$ of $21 \times 17.5 \mathrm{~mm}^{2}$.

Optical measurement techniques using visible light sources are limited in exploring near field internal information due to multiple scattering effects in the dense spray region close to the nozzle tip. X-ray radiography is used to overcome this limitation. X-rays can penetrate dense flow fields with relatively little scattering. Use of a high-flux monochromatic beam can provide a local quantitative measurement of the fuel mass distribution by measuring line of sight transmission (c.f. $[6,7,11,12,35-38])$. This technique is based on the Lambert-Beer law which relates the x-ray transmission to the fuel mass present in the beam path via

$$
\frac{I}{I_{0}}=e^{-\mu M}
$$

in which $I$ and $I_{o}$ are the transmitted and incident x-ray beam intensities, $\mu$ is the absorption coefficient determined by calibration of the fuel, and $M$ is the projected mass (units mass per area)

$$
M(x, y, t)=M=\int \rho d z
$$

with $\rho$ being density. Integrating projected mass $M$ across the spray gives the transverse integrated mass (TIM),

$$
T I M=\int M d y .
$$

TIM is normally expressed in units of $\mu \mathrm{g} / \mathrm{mm}$ and it will vary with axial $(x)$ position in the spray and time, although once steady injection conditions have been reached, TIM varies mostly with $x$ position.

X-ray radiography was performed at the 7-BM beamline of the Advanced Photon Source (APS) at Argonne National Laboratory [39]. In these experiments, a monochromatic x-ray beam of mean energy $8 \mathrm{keV}$ at $1.4 \%$ full width at half maximum bandpass was used. The beam was focused to a spot approximately $5 \times 6 \mu \mathrm{m}^{2}$ in size using a pair of $\mathrm{x}$-ray focusing mirrors. The beam focus was aligned with the spray, which was placed in a chamber pressurized with $\mathrm{N}_{2}$ at ambient temperature 
to 20 bar. This chamber was fitted with x-ray transparent polyimide windows. Time-resolved point measurements were combined to a 2D representation of the projected mass field by raster scanning the spray across the fixed beam position. Measurements were made on an unstructured grid of several hundred points, with increasingly fine resolution near the nozzle tip. Figure 1 illustrates the orientation of the APS spray chamber set-up, with the injector body mounted to the left spraying towards the right. The nozzle hole angle $\theta$ is defined as the angle subtended by the centrelines of the nozzle holes, with nozzle half-angle $\beta$ being defined as the angle subtended by the axis of the nozzle hole and the nozzle centerline. These angles are illustrated in Fig. 1. Actual setup and more detailed description can be found in, e.g. [36]. Each point measurement was captured with a temporal resolution of $3.68 \mu \mathrm{s}$ (the orbit period of the synchrotron storage ring). The reference intensity $I_{o}$ was determined by both the incoming beam intensity and that of the transmitted beam for several hundred microseconds before the spray event, normalizing out the absorption due to the ambient gas and other components in the beam path. Data for the optical imaging measurements are averaged over 200 spray events, while for x-ray measurements, data is averaged over 32 spray events at each position.

Diesel fuel used in the different facilities was different due to the varying experimental requirements. In the LTRAC experiments, standard ultra-low sulphur automotive diesel with a measured density $\rho_{l}$ at room temperature of $830 \mathrm{~kg} / \mathrm{m}^{3}$ was used. This fuel was also used for the single-hole nozzle x-ray radiography APS data [2]. For the twin-hole nozzle APS experiments, the diesel (Viscor 1487) was doped with a cerium additive (Rhodia DPX9) to enhance absorption giving a measured density at room temperature of $874 \mathrm{~kg} / \mathrm{m}^{3}$. The minor differences in fuel properties are not expected to have any significant influence on nozzle flow characteristics $[31,40]$.

\subsection{Image analysis}

To simplify characterisation of the two sprays of the THNs, the recorded image is split into the $-y$ and $+y$ sides relative to the $x$-axis (Fig. 1). These sides effectively represent the two individual sprays. The penetration of the leading edge is calculated separately for these sides as well as the penetration of the leading edge along the centerline ( $x$-axis) of the spray.

There are a number of options available for such calculations including binarisation [1], edge detection such as Canny [41], and strip-wise cross-correlation [3]. The first two methods are typically pixel accurate; the third, similar to PIV, is able to locate the edge with subpixel accuracy. Leading edge detection can provide the distribution of axial velocities (radial velocities are much smaller). A new approach is developed for this work [15] based on a direct quadratic function fit on the intensity profile along a one-pixel-wide strip of the region surrounding the spray leading edge. This operation, illustrated in Fig. 2, is very fast and sub-pixel accurate. Two thresholds, in grey values out of the 8-bit spray images, are used. A lower "threshold 1" is for skipping image noise and determining fitting points while a higher "threshold 2 " is for detecting the edge, which is reckoned to be the intersection between the function and the line of "threshold 2". The selection of "threshold 2" is similar to that in [14]. The black arrow points to the position defined as the edge if binarisation is used while the green arrow points to the so defined position using this method. To find the merging point of two individual jets, the threshold method is also used.

Experimental uncertainty estimated in spray tip penetration from use of this method at $95 \%$ confidence level typically reaches its maximum absolute value of around $\pm 0.07 \mathrm{~mm}( \pm 0.5 \%)$ for 15 $\mathrm{mm}$ penetration from the nozzle, while the maximum relative error of $\pm 0.06 \mathrm{~mm}( \pm 3.2 \%)$ occurs at $0.1 \mathrm{~mm}$ penetration from the nozzle. 


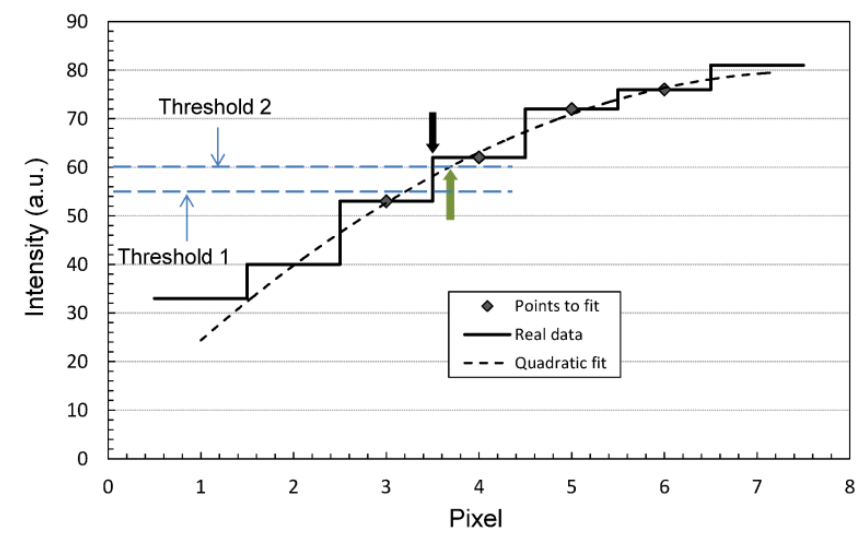

Figure 2: Quadratic function fit illustrated for 1-pixel-wide strip to find the spray leading edge [15].

\subsection{Nozzle Characterisation}

Electro-discharge machining was used to manufacture the twin-hole nozzles. No additional surface finishing was undertaken. Characterisation of the nozzle geometry was performed using high resolution X-ray computed tomography. The measurements were performed at the 7-BM beamline of the APS using a polychromatic beam [42]. A scintillator converted the x-ray images to visible light, which was recorded using a CMOS camera [30]. Each nozzle was rotated through $180^{\circ}$, and images were recorded at 2400 angles. Several images were taken at each angle; an ensemble median filter was used to remove high-energy pixels resulting from scattered radiation. The full 3D geometry of the nozzles was computed at a resolution of $1.17 \mu \mathrm{m} /$ pixel over a volume $2.25 \times 2.25 \times 1.4 \mathrm{~mm}^{2}$ using the Gridrec Fourier algorithm in TomoPy, an open source tomography toolkit developed at the APS [43]. Nozzle 3D images are then sliced in planes normal to the nozzle's axis from the orifice's entrance to its exit to determine the diameter and axis incline angle from the nozzle's axis direction. Figure 3 shows the cross section images of three THNs (cutting plane passes through the nozzle's axis). Tomography was not done for the SHN.

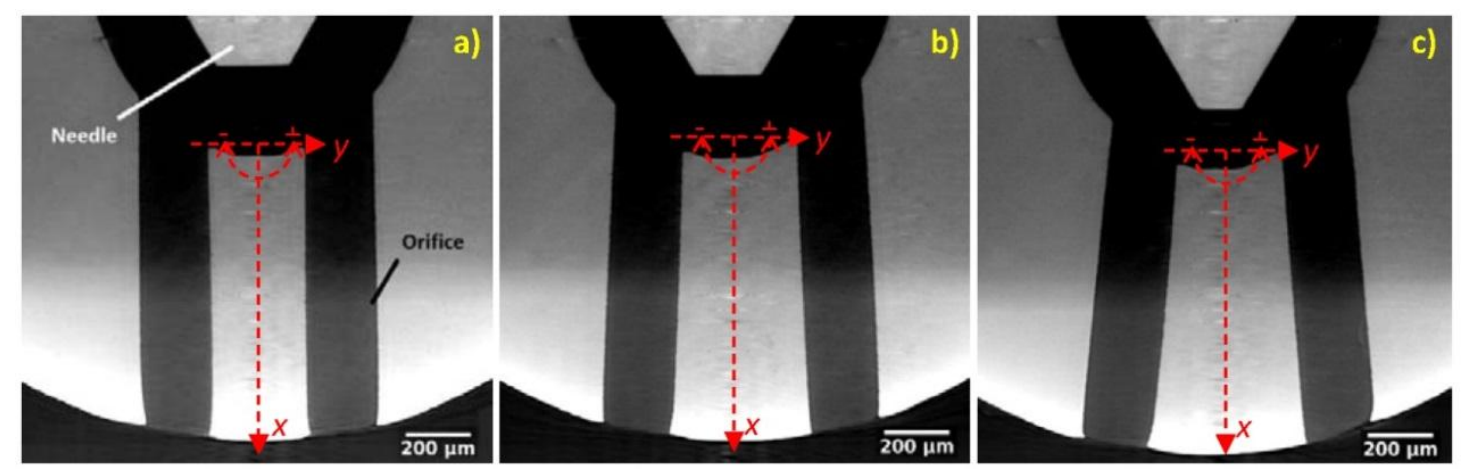

Figure 3: X-ray image of internal structures of: a) $0^{\circ}$, b) $5^{\circ}$ and c) $10^{\circ} \mathrm{THNs}$

Figure 4 shows the measured diameter throughout the nozzle passage for both $-y$ and $+y$ nozzle holes. The specified nozzle exit and passage diameter for all nozzles of $212 \mu \mathrm{m}$ was achieved for the $5^{\circ}$ nozzle, with remaining nozzles showing exit diameters both lower and higher than this value, Table 1. The variation of hole passage diameter is complex for these nozzles. All nozzles show an initially diverging passage diameter which supports cavitation $[32,44,45]$. This is followed by a later section which is converging and this is greatest for the $-y$ hole of the $0^{\circ}$ and $10^{\circ}$ nozzles. This feature helps to suppress cavitation [32,46], although here, this section occupies only a small part of the overall nozzle passage. The variation in nozzle diameter from inlet $d_{i}$ to outlet $d_{o}$ given by the $K$-factor,

$$
K=\frac{d_{i}-d_{o}}{10 \mu m}
$$


for each THN is listed in Table 1. Although these fall in the range typical of injectors of this size [25], when combined with length to diameter ratio of around 4.2 to 4.5 for these nozzles, modelling by [32] suggests geometric induced cavitation to be a strong possibility, with cavitation strength varying amongst the holes with $K$-factor.

The variation in the nozzle hole half-angle $\beta$ is also shown in Fig. 4 and tabulated as an average over the entire hole passage in Table 1. Half-angle is calculated by establishing the locus of the centroid of the nozzle passage. For the $0^{\circ}$ nozzle, although each hole is located symmetrically about the nozzle centerline, both holes are biased to the $+y$ side by around $3^{\circ}$. For the $5^{\circ}$ nozzle, the measured half-angles give an average hole angle of $\theta=5.8^{\circ}$, with a slight bias of $0.2^{\circ}$ to the $+y$ side. For the $10^{\circ}$ nozzle, the average hole angle is $\theta=10.3^{\circ}$ with a bias of $0.7^{\circ}$ to the $-y$ side.

An additional subtle feature of these nozzles is that the needle tip profile is slightly different for each nozzle, which will slightly alter the sac volume. Variations in both sac volume and needle shape are known to play a role in establishing the structure of the internal flow particularly during the initial needle lift period and to alter cavitation characteristics. Differences in the performance of each nozzle are therefore likely to result from these differences in geometry [26].

While the variations found above appear significant, they are typical of those found in the literature for nozzles manufactured using similar techniques (e.g. [25]) and as noted by [25], this points to the difficulty in manufacturing nozzles within tight tolerances.

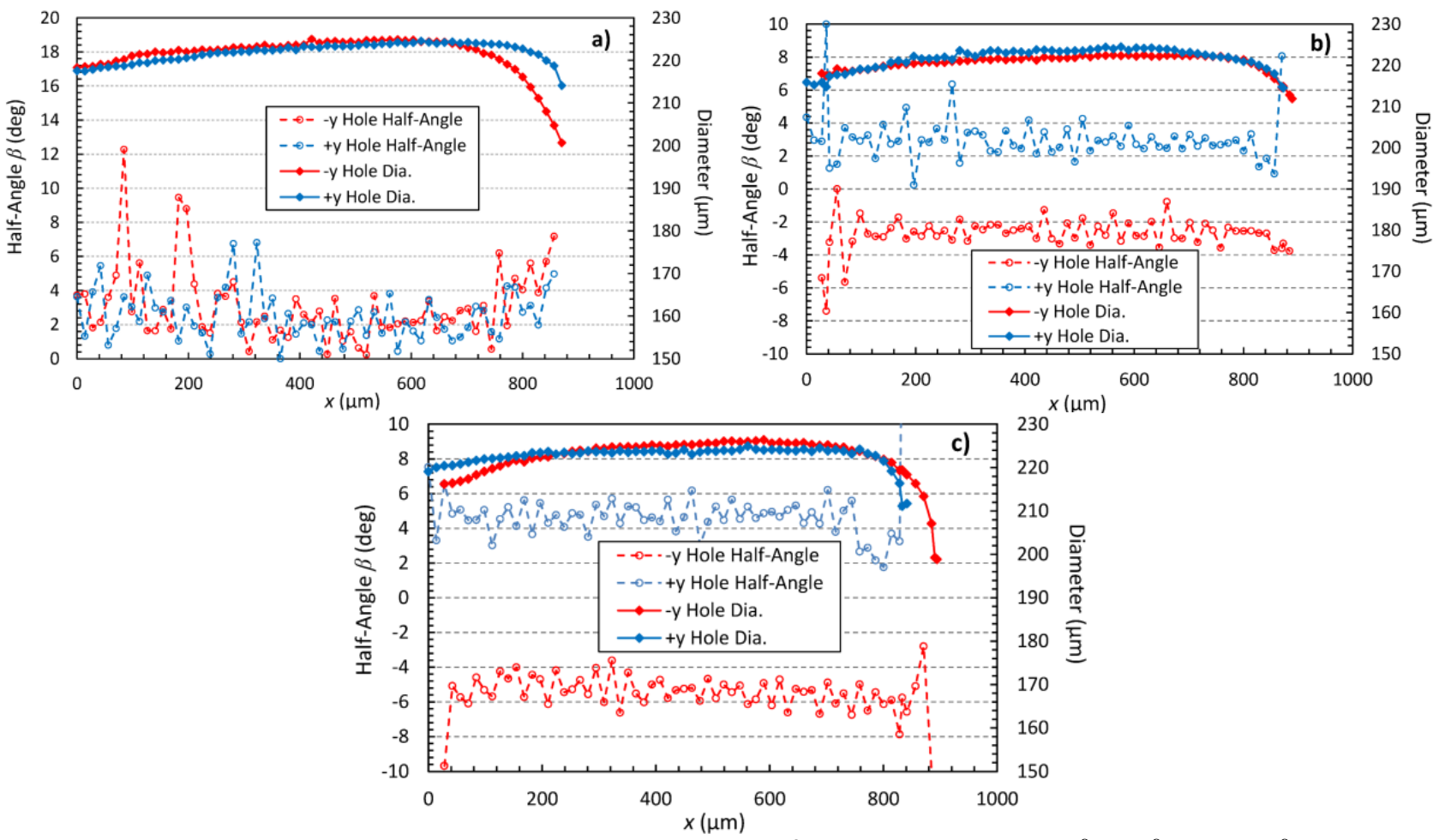

Figure 4: Variations of nozzle hole diameter and half-angle $\beta$ against $x$-position: a) $0^{\circ}$, b) $5^{\circ}$ and c) $10^{\circ} \mathrm{THNs}$

Table 1: Nozzle hole diameters and half angles

\begin{tabular}{|c|c|c|c|c|c|c|c|c|}
\hline Noz. & $\begin{array}{c}\boldsymbol{D}_{\boldsymbol{i}}(-\boldsymbol{y}) \\
(\mu \mathrm{m})\end{array}$ & $\begin{array}{c}\boldsymbol{D}_{\boldsymbol{i}}(+\boldsymbol{y}) \\
(\mu \mathrm{m})\end{array}$ & $\begin{array}{c}\boldsymbol{D}_{\boldsymbol{o}}(-\boldsymbol{y}) \\
(\mu \mathrm{m})\end{array}$ & $\begin{array}{c}\boldsymbol{D}_{\boldsymbol{o}}(+\boldsymbol{y}) \\
(\mu \mathrm{m})\end{array}$ & $\begin{array}{c}\boldsymbol{K} \text {-factor } \\
(-\mathrm{y})\end{array}$ & $\begin{array}{c}\boldsymbol{K} \text {-factor } \\
(+\mathrm{y})\end{array}$ & $\begin{array}{c}\overline{\boldsymbol{\beta}}(-\boldsymbol{y}) \\
(\mathrm{deg})\end{array}$ & $\begin{array}{c}\overline{\boldsymbol{\beta}}(+\boldsymbol{y}) \\
(\mathrm{deg})\end{array}$ \\
\hline $0^{\mathbf{o}} \mathrm{THN}$ & 218 & 217 & 200 & 214 & 1.8 & 0.3 & 2.8 & 3.1 \\
\hline $5^{\circ} \mathrm{THN}$ & 218 & 216 & 212 & 215 & 0.6 & 0.1 & -2.8 & 3.0 \\
\hline $10^{\circ} \mathrm{THN}$ & 216 & 219 & 199 & 211 & 1.7 & 0.8 & -5.5 & 4.8 \\
\hline SHN & & \multicolumn{2}{|c|}{200 (nominal) } & & & & \\
\hline
\end{tabular}




\section{RESULTS}

The results of this study are split into two phases, the initial transient and later steady state phases. While the optical technique focused on the transient phase, the x-ray technique covered both phases. Figure 5 shows the variation of transverse integrated mass TIM with time at selected $x$-positions from the $\mathrm{x}$-ray data for the $5^{\circ} \mathrm{THN}$ as an example (other nozzles having a similar profile). The time is relative to when the spray first appears (i.e. at $x=0.1 \mathrm{~mm}$ and set as time zero), this time reference is used in all later figures. As seen in this figure, all profiles have the same trend of an initial rapid rise from zero to a peak followed by a gradual decrease, shown as the "Transient" phase. The near constant TIM period following the transient phase is marked as "Steady State", after which TIM falls to zero when the trailing edge of the spray passed each $x$-position. These results resemble that of single-hole sprays [6,37] with the peaks representing the passing of the spray head, which is defined by a region of high TIM [1].

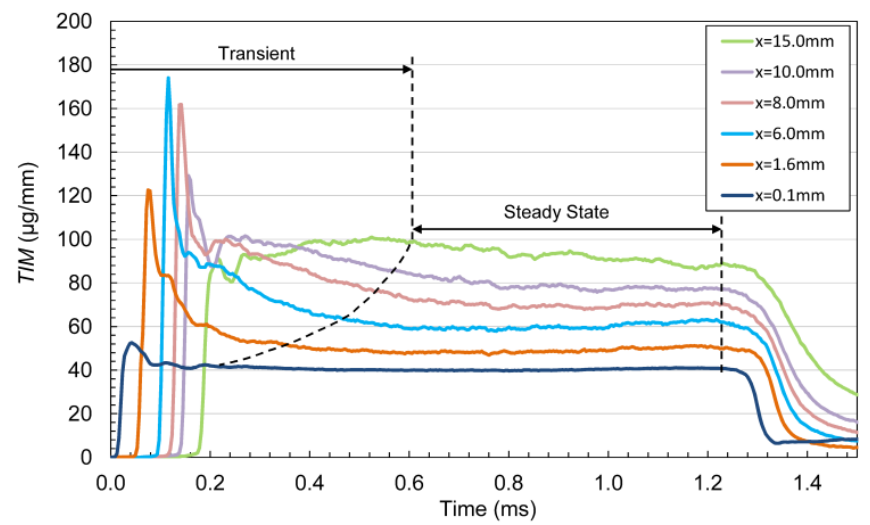

Figure 5: Variation of transverse integrated mass TIM with time at selected axial $x$-positions for $5^{\circ}$ THN. Shown in the figure are the transient and steady state phases of the injection for each position.

Figure 6 presents sequences of instantaneous images from three injection events obtained from the optical measurements for all THNs. The time stamp in each image indicates time after start of injection. The spray evolutions shown here correspond only to the short transient period in Fig. 5. For the THNs it takes the sprays less than $200 \mu$ s to reach the far end of the viewing window while taking between 200 to $600 \mu$ s to reach the steady state phase (Fig. 5). The separate sprays of the THNs are seen to quickly merge, with the extent of the merging varying with hole angle. For both the $0^{\circ}$ and $5^{\circ}$ nozzles, after merging, the spray takes the form of a single spray. For the $10^{\circ}$, two separate spray tips are still evident to the end of the imaged region. Nozzle hole dominance is also evident for the $10^{\circ}$ nozzle, with penetration from the $+y$ side hole leading the $-y$ side hole. The images shown here are similar to the $5^{\circ}$ and $10^{\circ}$ THNs examined in [20], although at longer time after start of injection. Images in [20] show a fully merged $5^{\circ}$ spray and separate heads for the $10^{\circ}$ spray at both 0.6 and $1 \mathrm{~ms}$ after start of injection, and there is also evidence of hole dominance.
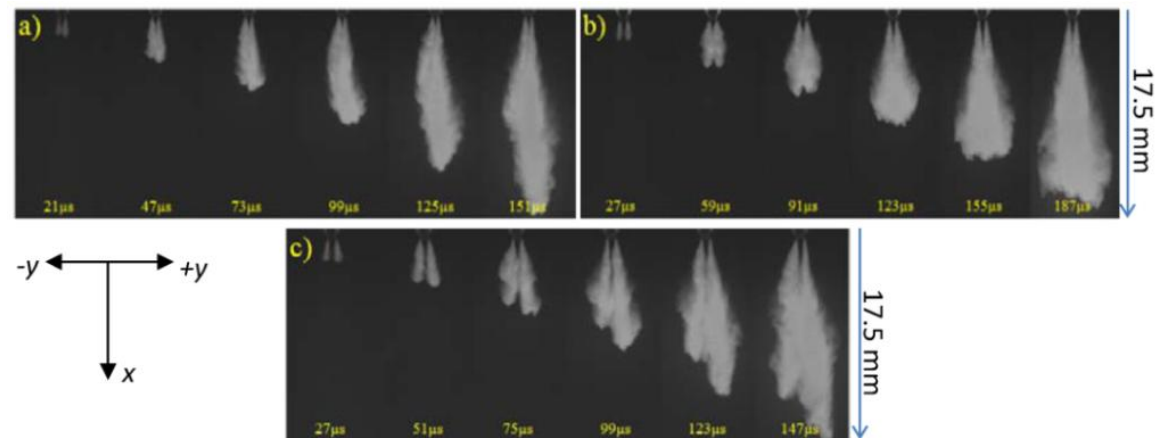

Figure 6: Sequences of spray images from optical imaging for THNs, time stamp in each image represents time after first appearance of fuel at the nozzle exit: a) $0^{\circ}$, b) $5^{\circ}$ and c) $10^{\circ}$. 
Figure 7 shows images of the projected mass $M$ measured from x-ray radiography (APS data) for the three THNs at a single time during the steady state phase of the injection. From Figs. 6 and 7, the effect of nozzle hole angle on spray structure is clearly evident as is the bias in nozzle hole halfangle discussed above; this is most clearly seen for the $0^{\circ}$ nozzle with its spray being directed slightly to the $+y$.

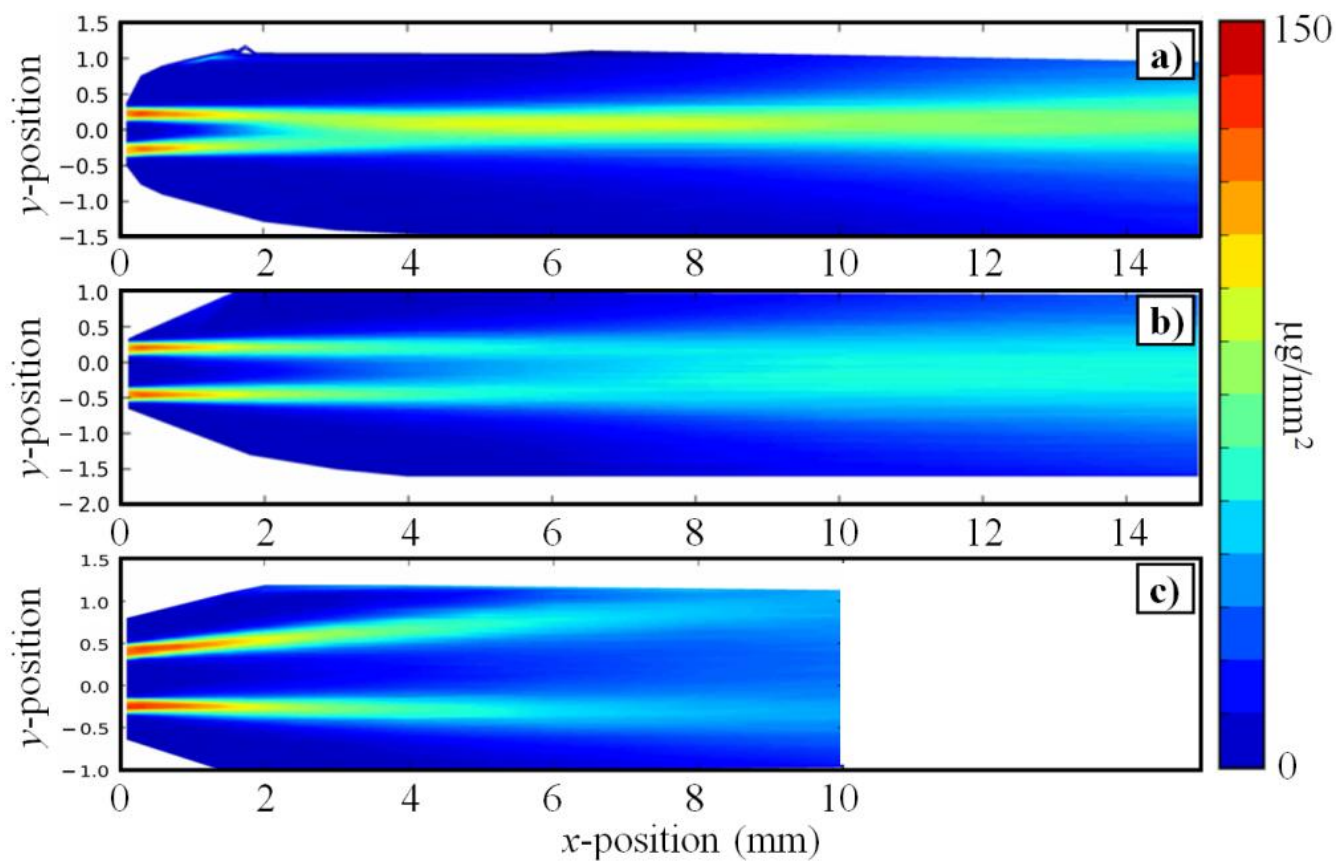

Figure 7: Steady state X-ray radiography measurements of projected mass $M$ : a) $0^{\circ}$, b) $5^{\circ}$ and c) $10^{\circ} \mathrm{THNs}$.

\subsection{Transient results}

Optical measurements of the spray penetration during the transient phase are shown in Fig. 8, with variation in merge length shown in Fig. 9. Merge length is defined by the length required for sprays from the two holes to merge determined by setting an image intensity threshold; see the Fig. 9 inset. For the THNs, mean penetration is shown for both sides of the spray and also along the nozzle centerline. From these comparisons, it is seen that the THNs have much slower penetration than the SHN. From Fig. 9, merging of the sprays typically first occurs after around 25-30 $\mu$ s from start of injection, i.e. 1.5 to $2 \mathrm{~mm}$ of penetration. Divergence by the THN nozzle mean penetration from SHN behavior has already commenced by this time. The SHN also shows a positive change in mean penetration gradient at around $30 \mu \mathrm{s}$, while for the THNs, this is delayed to around 90 to $100 \mu \mathrm{s}$. Slower needle lift has been observed for multi-hole nozzles relative to a similar SHN [13] with the possible cause being lower nozzle sac pressure due to their higher mass flow requirements. Although not shown in Fig. 5, this is supported here by a lower initial gradient leading to the peak in the near nozzle TIM profiles for the THNs relative to the SHN.

Spray entrainment is related to nozzle hole angle and its effect on mean penetration is complex for these nozzles. For the $0^{\circ} \mathrm{THN}$, both $-\mathrm{y}$ and $+\mathrm{y}$ nozzle holes have similar mean penetration, which is matched by the measured centerline penetration for this fully merged spray. Slowest penetration occurs for the $5^{\circ}$ THN, which from Fig. 6 also shows the largest spray spread suggesting entrainment to be greater than for the other two cases. The observed slower penetration for the $5^{\circ}$ THN is supported in the steady state phase by the distributions of projected mass shown in Fig. 7, in which it is shown to have a wider, merged single spray structure. Dominance by the $+y$ hole on spray structure and slower centre penetration is clearly evident for the $10^{\circ} \mathrm{THN}$. For the THNs in [20], penetration was found to be slower than for an area equivalent SHN, and systematically 
slower as hole angle increased from $5^{\circ}$ to $15^{\circ}$. An important difference between the nozzles used here and those in [20] was their use of nozzles with more than double the length to diameter ratio than the nozzles used here. Given the reduced propensity to cavitate for nozzles with higher length to diameter ratio [32], it is likely that past the nozzle merge point, spray to spray interaction is the most likely driver for slower penetration of the THNs found by [20]. While this is also likely to be the case here, the variation in penetration found also suggests the need to consider the role played by internal flow differences.

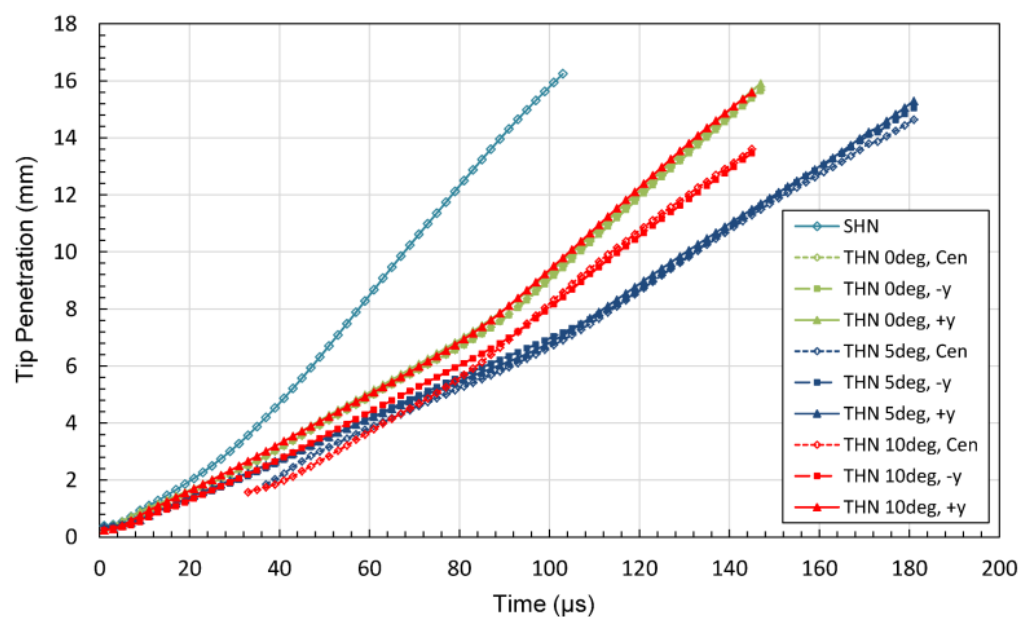

Figure 8: LTRAC optical measurements of mean spray tip penetration for all nozzles

Spray merging for the THNs occurs close to the nozzle and during the early stages it is dynamic, Fig. 9. For a fixed pressure condition, the merging process is expected to be influenced by the nozzle geometry, needle lift and entrainment, which will be dominated by the passage of the spray head. All nozzles show an initial decrease from a high merge length as the influence of the spray head reduces as it moves farther from the nozzle. This is followed in the case of the $5^{\circ}$ and $10^{\circ}$ nozzles by a steady increase as entrainment and nozzle flow become established. For the merge lengths in the range 1-2 mm, from Fig. 5, the peak TIM associated with the spray head occurs in the range $40-80 \mu$ s after start of injection. As expected for the greater nozzle hole angle, the $10^{\circ}$ nozzle shows much greater merge length than the $5^{\circ}$ nozzle. The $10^{\circ}$ also displays greater variation. The $0^{\circ}$ nozzle data lacks the increase in merge length in time following the initial high value. Uncertainties in this length are estimated to be small (typical maximum error is $\pm 4.1 \%$ near nozzle and minimum error $\pm 1.3 \%$ at shortest length). The merge lengths ultimately reached during steady state operation are indicated by projected mass distributions shown in Fig. 7, although it should be noted that differences in spatial resolution and measurement sensitivity will yield differences between the two measurement techniques.

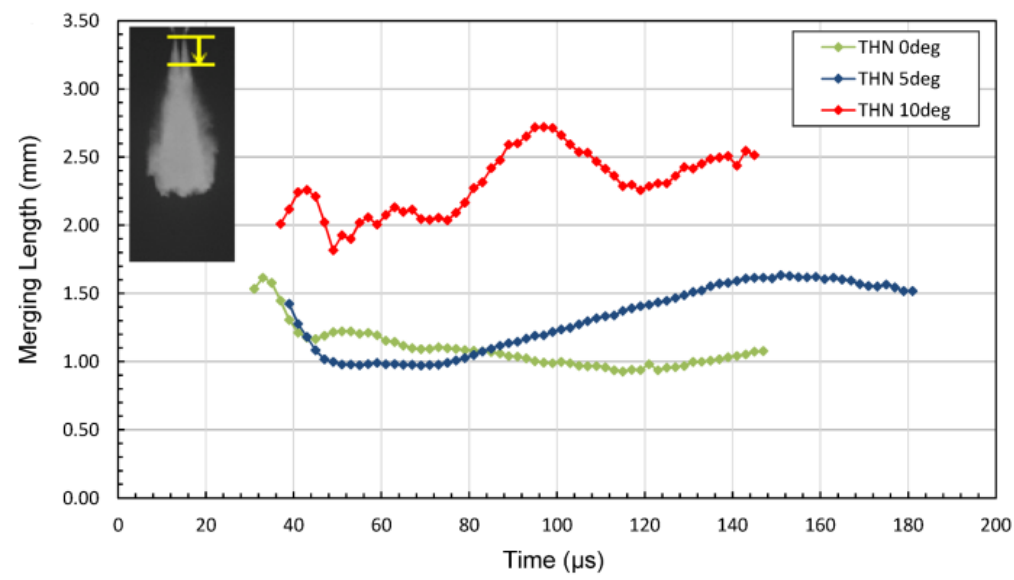

Figure 9: Evolution of spray merge length with time for all THNs. Inset shows definition of merge length. 


\subsection{Steady state results}

Steady state nozzle discharge coefficient $C_{D}$ of all nozzles at an injection pressure of 1000 bar and back pressure of $1 \mathrm{~atm}$ are shown in Table 2 . These were obtained by averaging repeated measurements of injected spray mass over $5.8 \mathrm{~ms}$ injection durations (injection duration being determined from imaged sprays). Values for the THNs are calculated using the nozzle's diameter measured at the exit as tabulated in Table 1. For the SHN, the value is based on the diameter provided by the manufacturer. These values are low compared to other published data, for example $C_{D} \approx 0.86$ for ECN spray A [47].

The nozzle cavitation number, using the definition given by [28]

$$
k=\frac{p_{i}-p_{v}}{p_{i}-p_{c}}
$$

for the injection pressure $p_{i}=1000$ bar and chamber pressure $p_{c}=20$ bar used here, is $k=1.02$ for a typical vapour fuel pressure of $p_{v}=20 \mathrm{kPa}$. This value along with the values of $C_{D}$ strongly suggests the possibility of cavitation in all nozzles [48]. Especially for the $5^{\circ}$ nozzle, the $C_{D}$ is very close to the theoretical minimum value of 0.61 for a cavitating sharp edge nozzle [49].

Table 2: Steady state flow conditions

\begin{tabular}{|c|c|c|c|c|c|c|c|c|c|}
\hline Nozzle & $\boldsymbol{C}_{\boldsymbol{D}}$ & $\begin{array}{c}\dot{\boldsymbol{V}} / \boldsymbol{A}_{\boldsymbol{n}} \\
\left(\mathrm{ml} / \mathrm{mm}^{2} \mathrm{~s}\right)\end{array}$ & $\begin{array}{c}\overline{\boldsymbol{T I} \boldsymbol{M}_{\boldsymbol{n}}} \\
(\mu \mathrm{g} / \mathrm{mm})\end{array}$ & $\begin{array}{c}\boldsymbol{\rho}_{\boldsymbol{l}} \\
\left(\mathrm{kg} / \mathrm{m}^{3}\right)\end{array}$ & $\begin{array}{c}\overline{\boldsymbol{\rho}_{\boldsymbol{n}}} \\
\left(\mathrm{kg} / \mathrm{m}^{3}\right)\end{array}$ & $\boldsymbol{C}_{\boldsymbol{\rho}}$ & $\begin{array}{c}\overline{\boldsymbol{U}_{\boldsymbol{n}}} \\
(\mathrm{m} / \mathrm{s})\end{array}$ & $\boldsymbol{C}_{\boldsymbol{v}}$ & $\boldsymbol{C}_{\boldsymbol{\rho}} \boldsymbol{C}_{\boldsymbol{v}}$ \\
\hline $0^{\circ} \mathrm{THN}$ & 0.675 & 318 & 20.2 & 874 & 597 & 0.684 & 461 & 0.974 & 0.666 \\
\hline $5^{\circ} \mathrm{THN}$ & 0.622 & 301 & 20.0 & 874 & 557 & 0.637 & 468 & 0.988 & 0.630 \\
\hline $10^{\circ} \mathrm{THN}$ & 0.695 & 329 & 20.8 & 874 & 628 & 0.719 & 453 & 0.956 & 0.688 \\
\hline SHN & 0.657 & 306 & 21.2 & 830 & 675 & 0.813 & 373 & 0.768 & 0.625 \\
\hline
\end{tabular}

The steady state volume flow per unit nozzle area $\dot{V} / A_{n}$ in Table 2 is calculated using the liquid fuel density $\rho_{l}$ listed, and $A_{n}$ is taken to be the total nozzle hole area. Fig. 10(a,c,e) shows variation of steady state TIM with $x$-position calculated from the x-ray data for all nozzles. TIM is averaged in time over the steady state injection period at each position. For the THNs, data is separated into $-\mathrm{y}$ and $+y$ holes $\left(T I M_{-y}, T I M_{+y}\right)$ to enable comparison with the single hole data and to investigate intra nozzle variation up to the point before the sprays merge; this is shown in finer detail in Fig. $10(\mathrm{~b}, \mathrm{~d}, \mathrm{f})$. Also presented for the THNs is the transverse integrated mass $\overline{T I M}$ for the entire spray divided by two for comparison to the SHN. From this figure it is seen that all nozzle holes show similar $\overline{\text { TIM }}$ values across the spray length and also near the nozzle exit at $x=0.1 \mathrm{~mm}$ for THNs and $0.2 \mathrm{~mm}$ for SHN, tabulated in Table 2 as $\overline{T I M_{n}}$. There is evidence of difference in TIM between holes of the individual THNs, particularly the $5^{\circ} \mathrm{THN}$, although no consistent trends are seen in respect of the variations in hole geometry.

The $\overline{T I M_{n}}$ data can be used to estimate mean nozzle exit flow density $\overline{\rho_{n}}$ by dividing $\overline{\text { TIM }}$ by $A_{n}$ [37], Table 2. These values are significantly lower than the liquid density $\rho_{l}$ of the diesel fuels used, particularly for the $5^{\circ} \mathrm{THN}$, indicating the presence of vapour. This can be further examined by equating the mean density to the area weighted liquid $\rho_{l}$ and vapour $\rho_{v}$ densities in the nozzle exit,

$$
\bar{\rho}_{n}=\rho_{l}\left(A_{l} / A_{n}\right)+\rho_{v}\left(1-A_{l} /_{A_{n}}\right)
$$

where $A_{l}$ is the nozzle area through which the liquid component flows. This can be rearranged as

$$
C_{\rho}=A_{l} /_{A_{n}}=\frac{\bar{\rho}_{n}-\rho_{v}}{\rho_{l}-\rho_{v}}
$$


which takes the form of a void fraction when written as $\alpha=1-C_{\rho}$. Assuming the vapour density to be small, $C_{\rho}=\overline{\rho_{n}} / \rho_{l}$ giving the values in Table $2 ; C_{\rho}$ ranges from 0.637 to 0.813 suggesting the presence of significant vapor quantities exiting the nozzle, with less in the SHN than for the THNs. $C_{\rho}$ can be related to $C_{D}$ by considering the steady state mass flow,

$$
\dot{m}=\bar{\rho}_{n} A_{n} \bar{U}_{n}=C_{D} \rho_{l} A_{n} U_{p}
$$

in which $U_{p}$ is the ideal pressure driven velocity and $\bar{U}_{n}$ the average velocity of the fluid exiting the nozzle. From this and the approximation of $C_{\rho}$, nozzle discharge coefficient can be given by

$$
C_{D}=C_{\rho}\left(\frac{\bar{U}_{n}}{U_{p}}\right)=C_{\rho} C_{v}
$$

in which the definition of velocity coefficient has been introduced. The product of $C_{\rho} C_{v}$ is shown in Table 2, and as expected it closely approximates the values of $C_{D}$ for all four nozzles, suggesting that exit flow density can be approximated by $\bar{\rho}_{n}=C_{D} \rho_{l} / C_{v}$.

An interesting difference between the SHN and THNs is SHN's higher $C_{\rho}$ value. Given the $C_{D}$ is similar for this nozzle, the relatively lower vapour content represented by the higher $C_{\rho}$ value must result in a lower average nozzle exit velocity $\bar{U}_{n}[32]$.
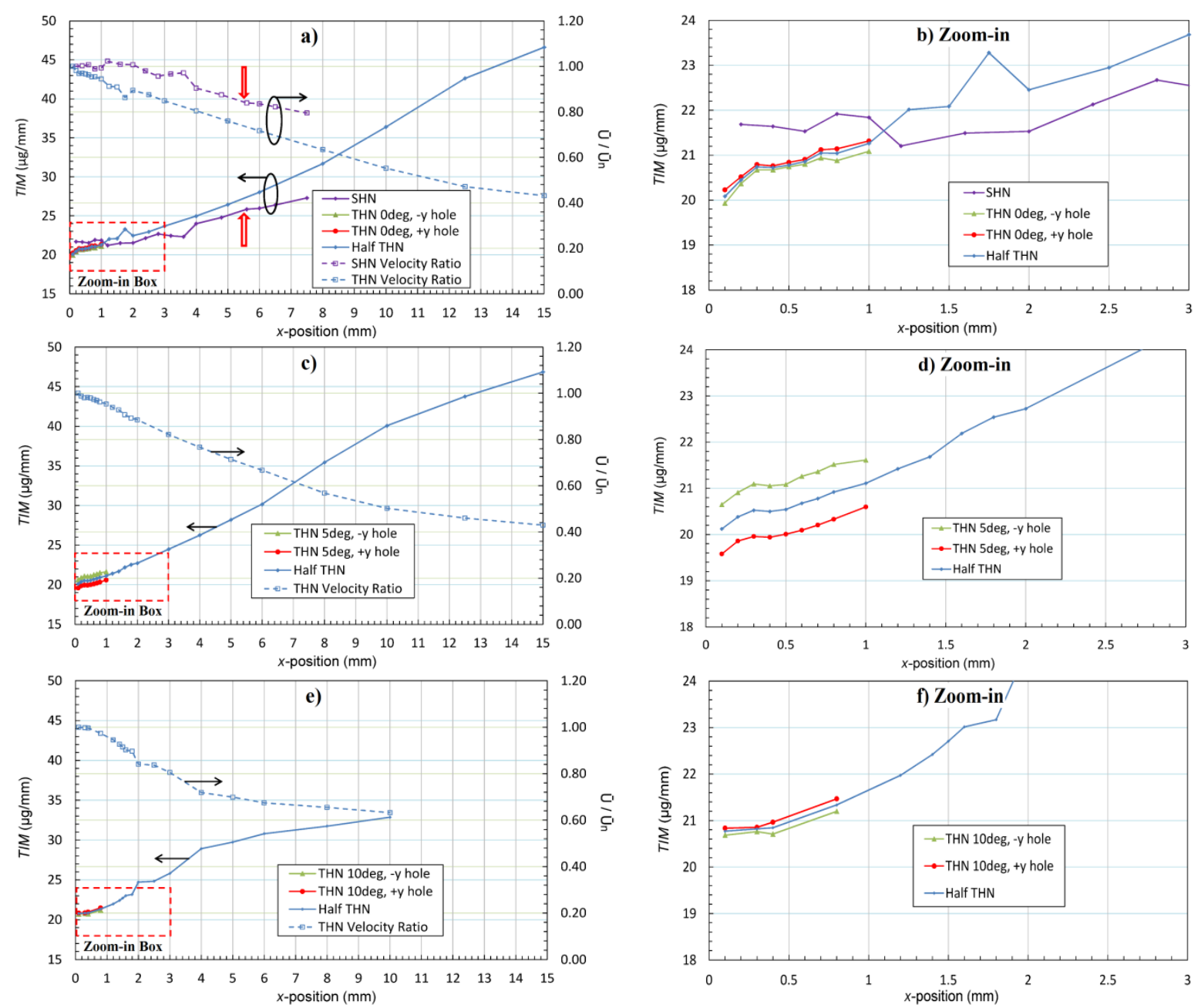

Figure 10: Steady state TIM along axial positions for both jets and half the spray found from the x-ray radiography measurements: a) THN $0^{\circ}$ and SHN, b) Zoom-in area in a); c) THN $5^{\circ}$, d) Zoom-in area in c); and e) THN $10^{\circ}$, f) Zoomin area in e). Shown in a), c) and e) are also the ratios of mass averaged axial velocity/near nozzle exit velocity. 
By scaling the mean value of nozzle exit $\overline{T I M_{n}}$ by the axial variation of $\overline{T I M}$, the axial decay in mean nozzle exit velocity $\bar{U}_{n}$ can be found [37],

$$
\frac{\bar{U}}{\bar{U}_{n}}=\frac{\overline{T I M}}{\overline{T I M}}
$$

which is shown in Fig. 10(a,c,e). As expected, the increased spread for the THNs gives rise to a greater decay in centerline velocity than for the SHN, although among the individual THNs, little difference in decay is evident.

\subsection{Discussion}

Further insight into the optical penetration data during the transient phase for each twin-hole nozzle can be gained by looking at the distribution of the difference in penetration as a function of time for all spray events. Figure 11 presents this as a PDF of the difference between the penetration of the $+\mathrm{y}$ and $-\mathrm{y}$ sides of the spray at each time record for all 200 spray events. The $0^{\circ}$ THN, Fig. 11a, shows a narrow distribution with a slight bias in the mean to the $+y$ side over the entire penetration of the spray and the width of the distribution remains fairly constant over the entire event. For the $5^{\circ}$ nozzle (Fig. 11b), the variability in penetration is greater. While the bias in the mean for this nozzle is not large, it displays a switching behaviour in side dominance as penetration increases. For the $10^{\circ}$ nozzle (Fig. 11c), the shot-to-shot variability is the greatest. As is evident from Fig. 6, there is a bias on the $+y$ side of this spray, and this bias increases with penetration suggesting dominance of the $+y$ hole. An additional feature of this nozzle is an increasing spread in the distribution with time which is a consequence of the twin head nature of this spray.
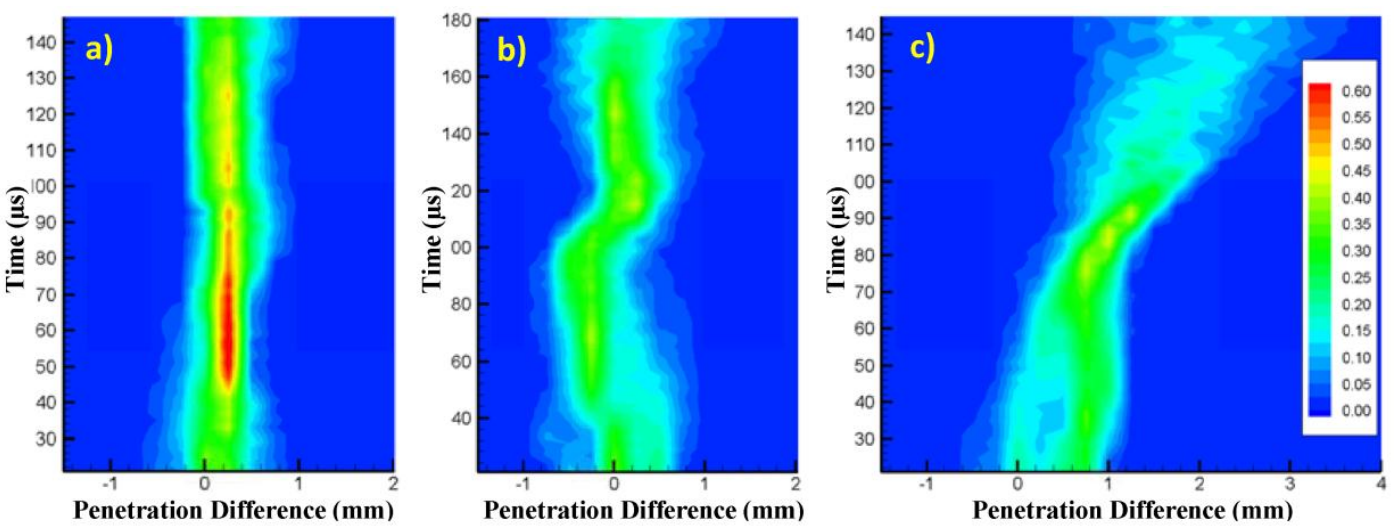

Figure 11: PDF of difference between $+y$ and $-y$ side penetrations of THNs: a) $0^{\circ}$, b) $5^{\circ}$ and c) $10^{\circ}$

Turbulent mixing at the leading edge of the spray will give rise to shot-to-shot variability in penetration [3] and this is reflected in the spread of the PDF at each instance in time, but it is unlikely to lead to switching in THN side dominance. Another possible source is nozzle geometry. However, while the $0^{\circ} \mathrm{THN}$ has a larger difference in $K$-factor and diameter than the $10^{\circ} \mathrm{THN}$ for its two nozzle holes (Table 1), it shows the least variability in penetration, suggesting these differences are not sufficient to give rise to the observed behavior. Variability in internal nozzle flow, whether from transient needle movement [50-52], instabilities in the internal flow, variation in line pressure [25] or cavitation dynamics [23] are possible causes.

The variation of near nozzle projected mass for individual nozzles is shown in Figs. 12 and 13. In these figures, the distribution of projected mass $M(y)$ is shown with time for the measurement position closest to the nozzle ( $x=0.1 \mathrm{~mm}$ for THNs and $x=0.2 \mathrm{~mm}$ for SHN) for the first $900 \mu \mathrm{s}$ from time zero, thus covering the whole transient phase and an initial part of the steady state phase. All nozzle holes show large scale instability in the peak mass initiating in the first $200 \mu \mathrm{s}$. This 
instability lasts for a period longer than that associated with the passage of the head of the spray; by $100 \mu$ s the head of the spray has moved to around 40 hole diameters from the nozzle. As each $M(y)$ value is the average of 32 individual spray events, the instability is highly repeatable. Past this, for the SHN the distribution becomes steady, although with a slight bias to the positive side of the nozzle. For THNs, the initial instability appears more complex with additional higher frequency components, which require significantly greater time to dampen. Longer dampening time is in keeping with the observation of the THNs having slower needle lift than the SHN.
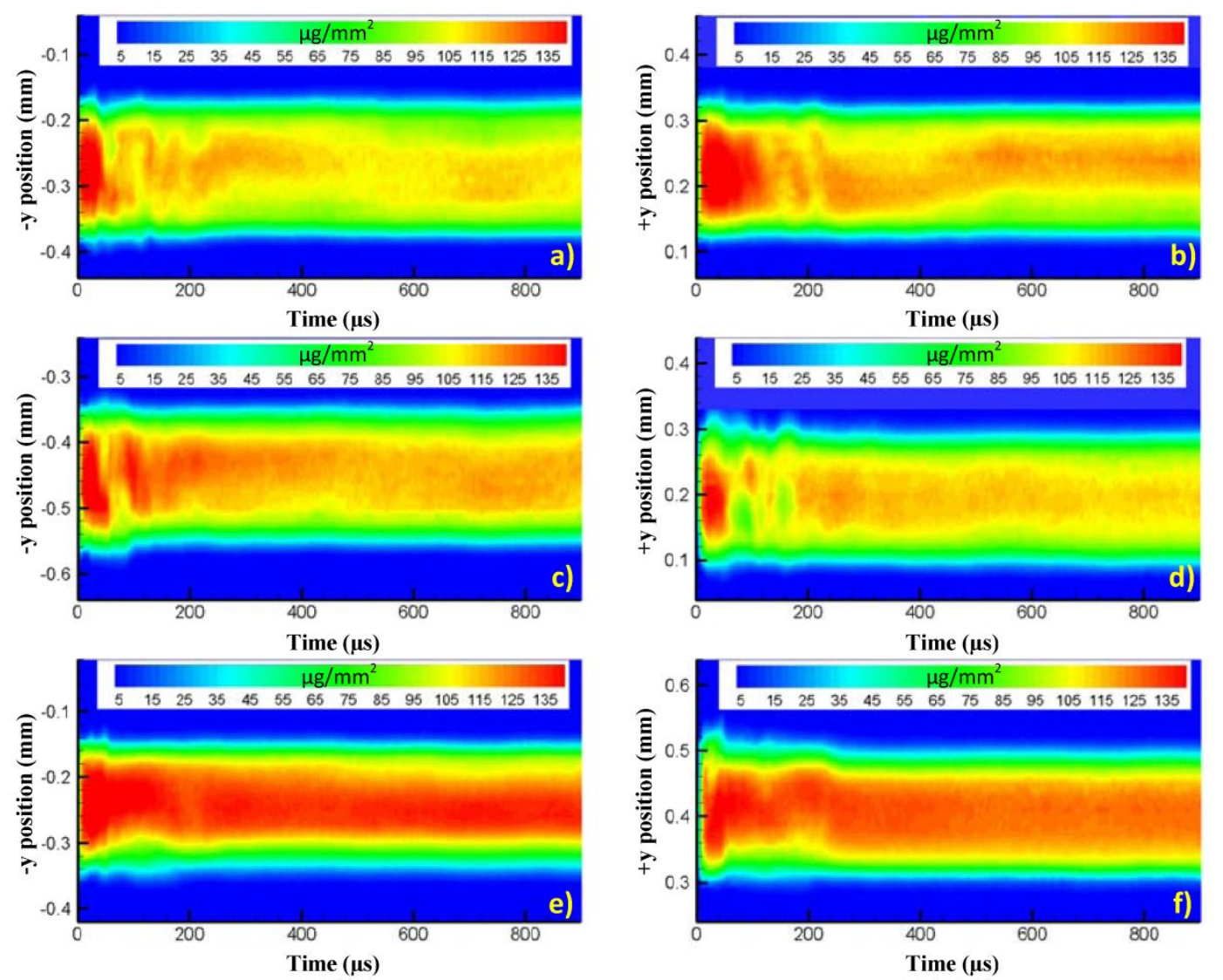

Figure 12: Evolution of projected mass $M(y, t)$ from x-ray radiography at $x=0.1 \mathrm{~mm}$ of the THNs for the first $900 \mu \mathrm{s}$ : a) $0^{\circ}$ (-y hole), b) $0^{\circ}$ (+y hole); c) $5^{\circ}(-y$ hole $)$, d) $5^{\circ}$ (+y hole); e) $10^{\circ}(-y$ hole $)$, f) $10^{\circ}$ (+y hole).

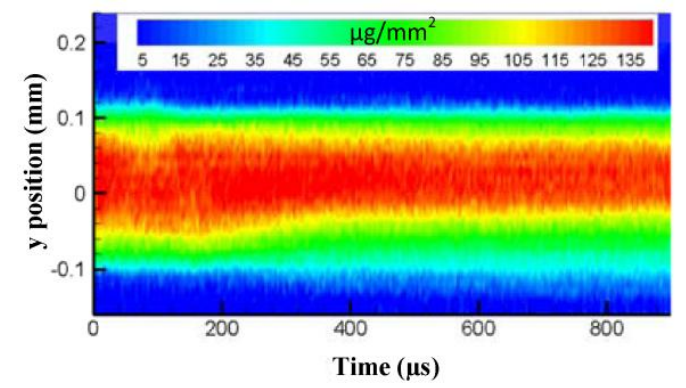

Figure 13: Evolution of projected mass $M(y, t)$ from x-ray radiography at $x=0.2 \mathrm{~mm}$ of the SHN for the first $900 \mu \mathrm{s}$.

Detailed measurements of needle lift for injectors similar to those used here by [25] showed that the first $200 \mu \mathrm{s}$ is dominated by the lift of the needle during which some throttling of the flow across the lifting needle is expected to occur. Past this point, highly repeatable oscillations both in line pressure and of the injector needle are known to happen [25], and the relative amplitude of the oscillation of internal nozzle pressure has also been shown to increase with increasing line pressure [53]. For line pressure, a $9 \%$ variation (4.5\% in mass flow) at 1500 bar with a period of around 380 $\mu$ s has been reported [25,54]. Needle oscillation is more complex with simultaneous axial and 
lateral oscillations with periods of $180 \mu$ s and $450 \mu$ s respectively having been reported [25]. A significant difference between the instabilities shown in Fig. 12 and the reported oscillations in the needle movement and line/nozzle pressure is that while needle movement and pressure variations continue over the duration of the injection, those found here in exit mass distribution have largely been damped by around $200 \mu \mathrm{s}$, which marks the end of the transient phase at this position. Past this time, all nozzles display a largely steady distribution in $M(y)$ with time, although differences in peak values occur from hole to hole for each nozzle. Given the nozzle discharge properties shown in Table 2, these differences are then likely due to cavitation from string or geometric sources.

Examining the form of the cavitation in the nozzle for the transient phase requires greater resolution than available here. However, for the steady state phase, it is possible by comparing the shape of the measured projected mass distribution to the projected mass profile which would result from different modelled vapour-liquid density profiles located at the nozzle exit. This is shown in Fig. 14 taking the measured $M(y)$ profile of the $+y$ hole of the $0^{\circ} \mathrm{THN}$ at $x=0.1 \mathrm{~mm}$ as an example. Four symmetric model density profiles are considered assuming a circular nozzle with the measured nozzle flow density $\bar{\rho}_{n}$ as the target value in all but one model. Model profiles considered are: (a) a profile in which the distribution of vapour with $\rho_{v}$ and liquid with $\rho_{l}$ is uniformly mixed across the nozzle area; (b) a distribution where there is a core flow of vapour surrounded by liquid; (c) a distribution where there is a core flow of liquid surrounded by vapour. The fourth model (d) assumes only liquid to leave the nozzle with density $\rho_{l}$, rather than the measured $\bar{\rho}_{n}$. The $M(y)$ profiles which give rise to these density distributions are compared with three measured steady state profiles of the projected mass sampled from the $0^{\circ} \mathrm{THN}$ at around $900 \mu \mathrm{s}$ (Fig. 12b, the sampling of the profiles is around $35 \mu \mathrm{s}$ apart). As expected, for the liquid only model (d), the centerline projected mass of $M \approx 187 \mu \mathrm{g} / \mathrm{mm}^{2}$ is higher than the measured average value of $M \approx 120 \mu \mathrm{g} / \mathrm{mm}^{2}$. For the separated phase models (b) and (c), a region of low $M$ would have to exist at the edge or centre of the spray, and in the case of the liquid core model, measured centerline projected mass would have to be $M \approx 155 \mu \mathrm{g} / \mathrm{mm}^{2}$. Similarity between the measured profile and the liquid core case (c) would be suggestive of geometrically induced cavitation, since for this form of cavitation vapour tends to exist at the spray periphery [30]. The model which provides the closest match is that of the uniform vapour-liquid mixture. String cavitation could yield such a distribution in the mean if the locally concentrated vortical vapour structures which dominate this form of cavitation [27] oscillated in the plane of the nozzle exit. Evidence for this can be found in the phase contrast images of [21], which show highly mobile vortex like structures in the near nozzle regions of the sprays examined.

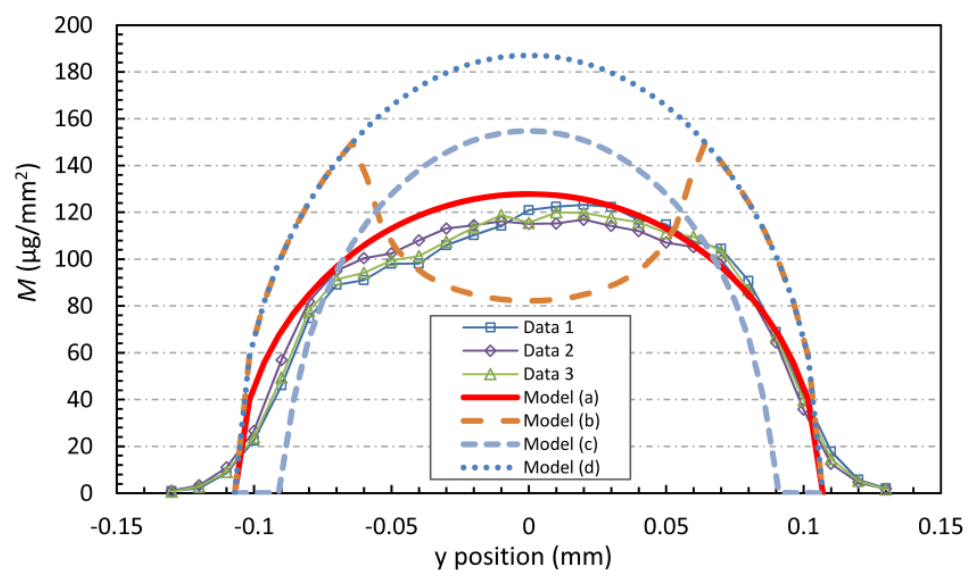

Figure 14: Modelled distributions of projected mass compared to the measured distribution for the $+\mathrm{y}$ hole of the $0^{0}$ nozzle at $x=0.1 \mathrm{~mm}$, see text. 


\section{CONCLUSIONS}

Optical imaging and x-ray radiography have been applied to investigate the development of diesel sprays produced from twin-hole nozzles with different subtended angles $\left(0^{\circ}, 5^{\circ}\right.$ and $\left.10^{\circ}\right)$ between the two holes. Results were compared with data from a research grade single-hole nozzle with similar hole dimensions. Characterisation of the twin-hole nozzles by x-ray tomography revealed variations in hole diameter and subtended angle, as well as needle tip shape. Although typical of variation found in similar injectors, these differences were found to play a role in the development of the structure of the sprays produced, particularly by imparting a bias in flow direction.

As expected, past the initial opening transient of the nozzles, spray merge length was found to increase with nozzle hole angle. All twin-hole nozzles displayed a reduced penetration relative to the single-hole nozzle, and this trend was established before the merging process was initiated. No systematic trend with nozzle hole angle was found with penetration, although in general, the larger the nozzle hole angle, the slower the penetration. Post spray merge, spray interaction is the likely cause of slower penetration, while lower sac pressure is thought to drive the slower pre-merge penetration. For steady flow conditions, axial decay in average velocity was found to be greater for all twin-hole nozzles than the single-hole nozzle. Steady state volume flow rate was found to be similar for each nozzle when expressed on a per unit hole area basis.

Dominance by one hole over the other was observed in the $10^{\circ}$ nozzle during transient operation, while the switching in hole dominance was observed for the $5^{\circ}$ twin-hole nozzle. Relative to the single-hole nozzle, instabilities in mass flow set up during the opening transient of the twin-hole nozzles took longer to dampen, and were found to be more complex, particularly for the $5^{\circ}$ twinhole case.

Measured steady state nozzle discharge coefficients for the nozzles ranged from 0.62 to 0.69 . Mean density of the exiting flow determined from x-ray radiography was found well below that of the liquid fuels used suggesting strong cavitation for these nozzles. Comparison of the measured nozzle exit projected mass distribution to modelled distributions suggests the cavitation process gives rise to vapour being widely distributed throughout the spray rather than appearing localised around the periphery of the spray. This points to the possibility of a chaotic cavitation process driven by highly complex internal flow.

\section{ACKNOWLEDGEMENT}

We acknowledge the Australian Research Council for funding the LTRAC component of this project. The x-ray component was performed at the 7-BM beam line of the APS at Argonne National Laboratory. Use of the APS is supported by the U.S. Department of Energy (DOE) under Contract No. DE-AC02-06CH11357. Argonne's fuel spray research is funded by DOE's Vehicle Technologies Program, Office of Energy Efficiency and Renewable Energy. We would like to express our gratitude to Gurpreet Singh and Leo Breton, team leaders at DOE, for their support. Mr. Matthew Wills is thanked for his help in processing the raw APS data.

\section{REFERENCES}

1. J. Kostas, D. Honnery and J. Soria, Time Resolved Measurements of the Initial Stages of Fuel Spray Penetration. Fuel 88 (2009), pp. 2225-37. 
2. J. Kostas, D. Honnery, J. Soria, A. Kastengren, Z. Liu, C.F. Powell and J. Wang, Effect of Nozzle Transients and Compressibility on the Penetration of Fuel Sprays. Applied Physics Letters 95 (2009), DOI: 10.1063/1.3182821.

3. J. Kostas, D. Honnery and J. Soria, A Correlation Image Velocimetry-Based Study of HighPressure Fuel Spray Tip Evolution. Exp. Fluid 51 (2011), pp. 667-78.

4. I.V. Roisman, L. Araneo and C. Tropea, Effect of Ambient Pressure on Penetration of a Diesel Spray. Int. J. Multiphase Flow 33 (2007), pp. 904-20.

5. P.C. Chen, W.C. Wang, W.L. Roberts and T. Fang, Spray and Atomization of Diesel Fuel and Its Alternatives from a Single-Hole Injector using a Common Rail Fuel Injection System. Fuel 103 (2013), pp. 850-61.

6. A. Kastengren, F. Tilocco, D. Duke, C. Powell, X. Zhang and S. Moon, Time-Resolved XRay Radiography of Sprays from Engine Combustion Network Spray A Diesel Injectors. Atomization and Sprays 24 (3) (2014), pp. 251-72.

7. A. Kastengren and C.F. Powell, Synchrotron X-Ray Techniques for Fluid Dynamics. Exp. in Fluids 55 (3) (2014), DOI: 10.1007/s00348-014-1686-8.

8. W. Zhong, Z. He, Q. Wang, Z. Shao and X. Tao, Experimental Study of Flow Regime Characteristics in Diesel Multi-Hole Nozzles with Different Structures and Enlarged Scales. Heat and Mass Transfer 59 (2014), pp. 1-10.

9. S. Moon, Y. Matsumoto, K. Nishida and J. Gao, Gas Entrainment Characteristics of Diesel Spray Injected by a Group-Hole Nozzle. Fuel 89 (2010), pp. 3287-99.

10. K. Nishida, J. Tian, Y. Sumoto, W. Long, K. Sato and M. Yamakawa, An Experimental and Numerical Study on Sprays Injected from Two-Hole Nozzles for DISI engines. Fuel 88 (2009), pp. $1634-42$.

11. A.I. Ramirez, S. Som, S.K. Aggarwal, A.L. Kastengren, E.M. El-Hannouny, D.E. Longman and C.F. Powell, Quantitative X-Ray Measurements of High-Pressure Fuel Sprays from a Production Heavy Duty Diesel Injector. Exp. Fluids 47 (2009), pp. 119-34.

12. P. Leick, A.L. Kastengren, Z. Liu, J. Wang and C.F. Powell, X-Ray Measurements of Mass Distributions in the Near-Nozzle Region of Sprays from Standard Multi-Hole Common-Rail Diesel Injection Systems. $11^{\text {th }}$ Triennial Inter. Annual Conference on Liquid Atomization and Spray Systems (ICLASS), Vail, Colorado USA, July 2009.

13. S. Moon, K. Komada, K. Sato, H. Yokohata, Y. Wada and N. Yasuda, Ultrafast X-Ray Study of Multi-Hole GDI Injector Sprays: Effects of Nozzle Hole Length and Number on Initial Spray Formation. Exp. Thermal and Fluid Sci. 68 (2015), pp. 68-81.

14. W.A. Abdelghaffar, K. Karimi and M.R. Heikal, Fuel Spray Penetration in High Pressure Diesel Engines. SAE Technical Paper No. 2007-01-0066, 2007.

15. D. Nguyen, D. Duke, A. Kastengren, C. Powell and D. Honnery, Common Rail Diesel Sprays from Twin-hole Nozzle. Proceedings of the Australian Combustion Symposium, Melbourne University, December 7-9, 2015. 
16. S.W. Park and R.D. Reitz, Optimization of Fuel/Air Mixture Formation for Stoichiometric Diesel Combustion using a 2-Spray-Angle Group-Hole Nozzle. Fuel 88 (2009), pp. 843-52.

17. F. Xue, F. Luo, H. Cui, A. Moro and L. Zhou, Numerical Analyses of Transient Flow Characteristics within Each Nozzle Hole of an Asymmetric Diesel Injector. Int. J. Heat and Mass Transfer 104 (2017), pp. 18-27.

18. H. Taghavifar, M.T. Shervani-Tabar and M. Abbasalizadeh, Numerical Study of the Effects of Injector Needle Movement and the Nozzle Inclination Angle on the Internal Fluid Flow and Spray Structure of a Group-Hole Nozzle Layout. Applied Mathematical Modelling 39 (2015), pp. 7718-33.

19. S.W. Park and R.D. Reitz, A Gas Jet Superposition Model for CFD Modeling of GroupHole Nozzle Sprays. Int. J. Heat and Fluid Flow 30 (2009), pp. 1193-201.

20. J. Gao, S.W. Park, Y. Wang, R.D. Reitz, S. Moon and K. Nishida, Simulation and Analysis of Group-Hole Nozzle Sprays using a Gas Jet Superposition Model. Fuel 89 (2010), pp. 3758-72.

21. X. Zhanga, S. Moon, J. Gao, E.M. Dufresne, K. Fezzaa and J. Wang, Experimental Study on the Effect of Nozzle Hole-to-Hole Angle on the Near-Field Spray of Diesel Injector using Fast Xray Phase-Contrast Imaging. Fuel 185 (2016), pp. 142-50.

22. A. Andriotis, M. Gavaises and C. Arcoumanis, Vortex Flow and Cavitation in Diesel Injector Nozzles. J. Fluid Mech. 610 (2008), pp. 195-215.

23. M. Gavaises and A. Androitis, Cavitation Inside Multi-Hole Injectors for Large Diesel Engines and Its Effect on the Near-Nozzle Spray Structure. SAE Technical Paper No. 2006-011114, 2006.

24. C. Arcoumanis, H. Flora, M. Gavaises and M. Badami, Cavitation in Real-Size Multi-Hole Diesel Injector Nozzles. SAE Technical Paper No. 2000-01-1249, 2000.

25. A.L. Kastengren, F.Z. Tilocco, C.F. Powell, J. Manin, L.M. Pickett, R. Payri and T. Bazyn, Engine Combustion Network (ECN): Measurements of Nozzle Geometry and Hydraulic Behavior. Atomization and Sprays 22 (12) (2012), pp. 1011-52.

26. Z. He, W. Zhong, Q. Wang, Z. Jiang and Z. Shao, Effect of Nozzle Geometrical and Dynamic Factors on Cavitating and Turbulent Flow in a Diesel Multi-Hole Injector Nozzle. Int. J. Thermal Sciences 70 (2013), pp. 132-43.

27. M. Gavaises, A. Andriotis, D. Papoulias, N. Mitroglou \& A. Theodorakakos, Characterization of String Cavitation in Large-scale Diesel Nozzles with Tapered Holes. Physics of Fluids, 21(5) (2009), 052107. http://doi.org/10.1063/1.3140940

28. W.H. Nurick, Orifice Cavitation and Its Effect on Spray Mixing. J. Fluids Eng. (1976), pp. 681-7.

29. D.P. Schmidt, C.J. Rutland and M.L. Corradini, A Numerical Study of Cavitating Flow Through Various Nozzle Shapes. SAE Paper 971597 (1997), pp. 117-26. 
30. D. Duke, A. Swantek, Z. Tilocco, A. Kastengren, K. Fezzaa, K. Neroorkar, M. Moulai, C. Powell and D. Schmidt, X-Ray Imaging of Cavitation in Diesel Injectors. SAE Technical Paper No. 2014-01-1404, 2014.

31. Z. He, Z. Shao, Q. Wang, W. Zhong and X. Tao, Experimental Study of Cavitating Flow inside Vertical Multi-Hole Nozzles with Different Length-Diameter Ratios Using Diesel and Biodiesel. Exp. Therm. Fluid Sci., 60 (2015), pp. 252-62.

32. Z.Y. Sun, G.X. Li, C. Chen, Y.S. Yu and G.X. Gao, Numerical Investigation on Effects of Nozzle's Geometric Parameters on the Flow and the Cavitation Characteristics within Injector's Nozzle for a High-Pressure Common-Rail DI Diesel Engine. Energy Conversion and Management 89 (2015), pp. 843-61.

33. N. Mason-Smith, D.J. Duke, A.L. Kastengren, D. Traini, P.M. Young, Y. Chen, D.A. Lewis, D. Edgington-Mitchell and D. Honnery, Revealing pMDI Spray Initial Conditions: Flashing, Atomisation and the Effect of Ethanol. Pharm Res (2017). doi:10.1007/s11095-017-2098-2.

34. D. Nguyen and D. Honnery, Combustion of Bio-Oil Ethanol Blends at Elevated Pressure. Fuel 87 (2008), pp. 232-43.

35. A.L. Kastengren, C.F. Powell, Y.J. Wang and J. Wang, Study of Diesel Jet Variability Using Single-Shot X-Ray Radiography. Proceedings of the ASME Internal Combustion Engine Division 2007 Fall Technical Conference ICEF2007-1663, Charleston, South Carolina USA, October 2007.

36. A.L. Kastengren, C.F. Powell, Y. Wang, K.S. Im and J. Wang, X-Ray Radiography Measurements of Diesel Spray Structure at Engine-Like Ambient Density. $21^{\text {st }}$ Annual Conference on Liquid Atomization and Spray Systems (ILASS), Orlando, Florida USA, May 2008.

37. A.L. Kastengren, C.F. Powell, S.K. Cheong, Y. Wang, K.S. Im, X. Liu, J. Wang and T. Riedel, Determination of Diesel Spray Axial Velocity Using X-Ray Radiography. SAE Technical Paper No. 2007-01-0666, 2007.

38. A.L. Kastengren, C.F. Powell, Z. Liu and J. Wang, Time Resolved, Three Dimensional Mass Distribution of Diesel Sprays Measured with X-Ray Radiography. SAE Technical Paper No. 2009-01-0840.

39. A.L. Kastengren, C.F. Powell, D. Arms, E.M. Dufresne, HH. Gibson and J. Wang, The 7BM Beamline at the APS: A Facility for Time-Resolved Fluid Dynamics Measurements. Journal of Synchrotron Rad. 19 (4) (2012), pp. 654-7.

40. A.K. Agarwal and V.H. Chaudhury, Spray Characteristics of Biodiesel/Blends in A High Pressure Constant Volume Spray Chamber. Exp. Therm. Fluid Sci., 42 (2012), pp. 212-8.

41. J. Canny, A Computational Approach to Edge Detection. IEEE Trans. Pattern Anal. Mach. Intel. 8 (6) (1986), pp. 679-98.

42. K. Matusik, D. Duke, C. Powell and A. Kastengren, High Resolution X-Ray Tomography of Injection Nozzles. $28^{\text {th }}$ Annual Conference on Liquid Atomization and Spray Systems (ILASS), Dearborn, Michigan USA, May 2016. 
43. D. Gursoy, F. De Carlo, X. Xiao and C. Jacobsen, TomoPy: A Framework for the Analysis of Synchrotron Tomographic Data. Journal of Synchrotron Radiation 21 (2014), pp. 1188-93.

44. F. Payri, R. Payri, F.J. Salvador and J. Martínez-López, A Contribution to the Understanding of Cavitation Effects in Diesel Injector Nozzles through a Combined Experimental and Computational Investigation. Computers and Fluids 58 (2012), pp. 88-101.

45. A. Sou, M.I. Maulana, K. Isokazi, S. Hosokawa \& A. Tomiyama, Effects of Nozzle Geometry on Cavitation in Nozzles of Pressure Atomizers. Journal of Fluid Science and Technology, 3(5) (2008), pp. 622-32.

46. R. Payri, X. Margot and F.J. Salvador, A Numerical Study of the Influence of Diesel Nozzle Geometry on the Inner Cavitating Flow. SAE Technical Paper No. 2002-01-0215, 2002.

47. A.L. Kastengren, F.Z. Tilocco, C.F. Powell, J. Manin, L.M. Pickett, R. Payri \& T. Bazyn, Engine Combustion Network (ECN): Measurements of Nozzle Geometry and Hydraulic Behavior. Atomization and Sprays, 22 (12) (2012), pp. 1011-52.

48. J.M. Desantes, R. Payri, J.M. Pastor and J. Gimeno, Experimental Characterization of Internal Nozzle Flow and Diesel Spray Behavior. Part 1: Non-Evaporating Conditions. Atomization and Sprays 15 (2005), pp. 489-516.

49. D.P. Schmidt and M.L. Corradini, The Internal Flow of Diesel Fuel Injector Nozzles: A Review. Int. J. Engine Research 2 (1) (2001), pp. 1-22.

50. F. Payri, R. Payri, M. Bardi and M. Carreres, Engine Combustion Network - Influence of the Gas Properties on the Spray Penetration and Spreading Angle. Exp. Therm. Fluid Sci., 53 (2014), pp. 236-43.

51. A.L. Kastegren, C.F. Powell, Z. Liu, K. Fezza and J.Wang, High-Speed X-Ray Imaging of Diesel Injector Needle Motion. Proceedings of the ASME Internal Combustion Engine Division 2009 Spring Technical conference ICES2009-76032, Milwaukee, Wisconsin, USA, May 2009.

52. C.F. Powell, A.L. Kastegren. Z. Liu and K. Fezza, The Effects of Diesel Injector Needle Motion on Spray Structure. Proceedings of the ASME 2009 Internal Combustion Engine Division 2009 Fall Technical Conference ICEF2009-14076, Lucerne, Switzerland, September 2009.

53. X. Wang, K. Lib and W. Su, Experimental and Numerical Investigations on Internal Flow Characteristics of Diesel Nozzle under Real Fuel Injection Conditions. Exp. Therm. Fluid Sci., 42 (2012), pp. 204-11.

54. L. Pickett, C. Genzale, G. Bruneaux, L. Malbec, L. Hermant, C. Christiansen and J. Schramm, Comparison of Diesel Spray Combustion in Different High-Temperature, High-Pressure Facilities. SAE Int. J. Engines 3 (2010), pp. 156-81. 